\title{
Urinary Glycosaminoglycans Excretion and the Effect of Dimethyl Sulfoxide in an Experimental Model of Non-Bacterial Cystitis
}

\author{
Roberto Soler, Homero Bruschini, Jose C. Truzzi, Joao R. Martins, Niels O. Camara, Maria T. \\ Alves, Katia R. Leite, Helena B. Nader, Miguel Srougi, Valdemar Ortiz
}

Division of Urology (RS, JCT, VO), Division of Molecular Biology (JRM, HBN), Division of Nephrology (NOC) and Division of Pathology (MTA), Federal University of Sao Paulo, UNIFESP, and Division of Urology (HB, KRL, MS), University of Sao Paulo, USP, Sao Paulo, SP, Brazil

\begin{abstract}
Purpose: We reproduced a non-bacterial experimental model to assess bladder inflammation and urinary glycosaminoglycans (GAG) excretion and examined the effect of dimethyl sulfoxide (DMSO).

Materials and Methods: Female rats were instilled with either protamine sulfate (PS groups) or sterile saline (control groups). At different days after the procedure, $24 \mathrm{~h}$ urine and bladder samples were obtained. Urinary levels of hyaluronic acid (HA) and sulfated glycosaminoglycans (S-GAG) were determined. Also to evaluate the effect of DMSO animals were instilled with either 50\% DMSO or saline 6 hours after PS instillation. To evaluate the effect of DMSO in healthy bladders, rats were instilled with 50\% DMSO and controls with saline.

Results: In the PS groups, bladder inflammation was observed, with polymorphonuclear cells during the first days and lymphomononuclear in the last days. HA and S-GAG had 2 peaks of urinary excretion, at the $1^{\text {st }}$ and $7^{\text {th }}$ day after PS injection. DMSO significantly reduced bladder inflammation. In contrast, in healthy bladders, DMSO produced mild inflammation and an increase in urinary HA levels after 1 and 7 days and an increase of S-GAG level in 7 days. Animals instilled with PS and treated with DMSO had significantly reduced levels of urinary HA only at the $1^{\text {st }}$ day. Urinary S-GAG/Cr levels were similar in all groups.

Conclusions: Increased urinary levels of GAG were associated with bladder inflammation in a PS-induced cystitis model. DMSO significantly reduced the inflammatory process after urothelial injury. Conversely, this drug provoked mild inflammation in normal mucosa. DMSO treatment was shown to influence urinary HA excretion.
\end{abstract}

Key words: cystitis; dimethyl sulfoxide; glycosaminoglycans; rats; protamines

Int Braz J Urol. 2008; 34: 503-11

\section{INTRODUCTION}

Interstitial cystitis (IC) is a heterogeneous syndrome, diagnosed mainly in women, characterized by painful bladder symptoms, nocturia, urinary frequency and urgency. These symptoms usually appear acutely and follow a waxing and waning course (1).
Dimethyl sulfoxide (DMSO) has been used as an intravesical therapy for IC due to its anti-inflammatory and analgesic properties. Although its mechanisms of action have not yet been fully elucidated, it is a well established treatment for IC, with proven feasibility (2).

Impaired barrier function of bladder epithelium and subsequent infiltration of urine contents are 
expected initial events in the pathophysiology of IC. Glycosaminoglycans (GAG) are complex long-chain polysaccharides components of the extra cellular matrix and cell surface, which play multiple physiological functions (3). The GAG layer is thought to create a hydrophilic coating in the underlying cells by binding water, via their sulfated groups. Alterations of the urothelial GAG layer, which may lead to higher bladder permeability, might also be present in IC (4).

Considering the lack of a defined cause and also generally effective treatments, experimental models of IC are a challenging field. Protamine sulfate (PS) has been used in experimental models of IC, which at a low concentration $(10 \mathrm{mg} / \mathrm{mL})$ represents a noncytotoxic affront to urothelial barrier instead of a bladder irritant $(5,6)$ PS is a polycationic quaternary amine which changes the permeability of the urothelium and other types of epithelia (7). In this study, we examined the urinary GAG excretion and its correlation with inflammation and the effect of treatment with DMSO in an experimental model of IC, induced by PS.

\section{MATERIALS AND METHODS}

\section{Animals and Induction of Bladder Inflammation}

Adult female Wistar rats (180 to $200 \mathrm{~g}$ ) were housed in light and temperature controlled rooms on a $12 / 12$ hours light-dark cycle, with free access to water and food, prior to their use in experimental studies. All animal studies were carried out with the approval of the University Ethics Committee.

Rats were anesthetized with an intraperitoneal injection of xylazine $(4 \mathrm{mg} / \mathrm{kg})$ and ketamine $(90 \mathrm{mg} /$ $\mathrm{kg}$ ). External genitalia were cleansed with povidoneiodine and a small quantity of $2 \%$ lidocaine lubricant was applied to the external urethra. A 24 gauge $3 / 4$-inch catheter was inserted into the bladder and the urine was drained. Bladder injury was induced with grade X PS (Sigma, St. Louis, MO), $10 \mathrm{mg}$ in $200 \mu \mathrm{L}$ sterile $0.9 \%$ saline applied intravesically. After 30 minutes, the bladder was drained and washed with $200 \mu \mathrm{L}$ $0.9 \%$ saline. The catheter was removed and the rats were allowed to recover. Control rats were initially injected with $200 \mu \mathrm{L}$ saline and the same procedure was followed.

\section{Experimental Groups}

PS groups ( $n=7$ per day) and control groups $(\mathrm{n}=5$ per day) were analyzed at different days following the procedure: $1^{\text {st }}$ to $7^{\text {th }}, 10$ th and 14 th days (total $\mathrm{n}=108$ ). The rats were housed 24 hours prior to sacrifice in a metabolic cage in order to collect urine. The bladder was removed and fixed in normal $10 \%$ buffered formalin and urine was immediately centrifuged to remove exfoliated cells and urinary debris and stored at $-20^{\circ} \mathrm{C}$ for further analyses. Five non-manipulated animals (day 0 ) also had their urine collected. Prior to assay, the creatinine $(\mathrm{Cr})$ content was measured by a kit purchased from Sigma Chemical Co. (St. Louis, MO.).

To evaluate the effect of DMSO on this experimental model, 6 hours after PS instillation, the animals were intravesically instilled with 200 $\mu \mathrm{L}$ of either $50 \%$ DMSO $(\mathrm{n}=5$ per day) or saline ( $\mathrm{n}$ $=5$ per day) for 30 minutes. To assess the effect of DMSO in healthy bladders, rats $(n=5$ per day) were instilled with $200 \mu \mathrm{L} \mathrm{50 \%} \mathrm{DMSO}$ and controls ( $\mathrm{n}=$ 5 per day) with $200 \mu \mathrm{L}$ saline for 30 minutes. One and 7 days afterwards, 24 hrs urine was collected and bladders were removed for histopathological analysis.

\section{Histopathology}

Approximately $5 \mu \mathrm{m}$ thick paraffin sections were stained with hematoxylin and eosin for general morphology. The samples were blinded reviewed by two pathologists. Edema and vascular congestion were graded 0 (absent), 1 (mild), 2 (moderate) and 3 (severe). Each inflammatory cell type was counted (polymorphonuclear - PMN, mast cell and lymphomononuclear - LMN) in 5 cross sections at X400 magnification, at the most infiltrated area.

\section{Measurement of Urinary Hyaluronic Acid}

Urinary hyaluronic acid (HA) levels were measured by a noncompetitive and nonisotopic fluoroassay. Plates were coated with hyaluronan binding 
proteins (HABP) and successively incubated with samples containing standard solutions of HA or urine samples from the different groups, biotinconjugated HABP and europium-labeled streptavidin (Amersham Life Science, Buckinghamshire, England). After release of europium from streptavidin with enhancement solution (Perkin-Elmer Life Sciences-WaIlac Oy, Turku, Finland) the final fluorescence was measured in a fluorometer (8). HA concentration was normalized to $\mathrm{Cr}$ and expressed in $\mathrm{ng} / \mathrm{mg} \mathrm{Cr}$.

\section{Measurement of Urinary Sulfated GAG}

Two milliliters of urine from the different groups of animals were applied in a Sephadex G25 column, equilibrated with distilled water, which separates GAG from salt, pigments, smaller compounds and other impurities. The inclusion volume was discarded and the following $4 \mathrm{~mL}$ flow-through were collected, vacuum dried and then, dissolved in $10 \mu \mathrm{L}$ of distilled water and kept frozen at $-20^{\circ} \mathrm{C}$ for analysis. Afterwards, $5 \mu \mathrm{L}$ of the stored samples and $5 \mu \mathrm{L}$ of an aqueous mixture of $1 \mathrm{mg} / \mathrm{mL}$ of standard GAG (Chondroitin 4- and 6-sulfate (CS), Dermatan sulfate (DS) and Heparan sulfate (HS)) were applied in $0.2-\mathrm{cm}$ thick agarose gel slabs $(0.55 \%$ agarose in $50 \mathrm{nM} \mathrm{1.3-diaminopropane/acetate} \mathrm{buffer,} \mathrm{pH}$ $9.0)$ to proceed with the electrophoresis (9). The gel slabs were then fixed with $0.1 \%$ cetyltrimethyl-ammonium bromide, dried, stained with toluidine blue and quantified by densitometry at $595 \mathrm{~nm}$. GAG concentration was normalized to $\mathrm{Cr}$ and expressed in $\mu \mathrm{g} / \mathrm{mg} \mathrm{Cr}$.

\section{Statistical Analysis}

Comparison between treated groups and their respective control groups was carried out by performing Student's-t-test for parametric data and MannWhitney U test for non-parametric data. Comparison between all the groups was carried out by ANOVA, when normal distribution or Kruskal-Wallis test, without normal distribution, followed by Dunn's or Tukey multiple comparison tests. We used the Sigma Stat software for Windows, 2.0, 1999 (SSPS Inc., Chicago, IL).

\section{RESULTS}

\section{Histopathology}

\section{PS and Control Groups}

Edema was more pronounced on the first three days after PS injection. Vascular congestion grade was in overall higher in PS groups and was considered statistically different on the first three days and between the $6^{\text {th }}$ and $10^{\text {th }}$ days (Figure-1A).

The bladder sections showed focal inflammatory changes. Control animals had low number of inflammatory cells during all analyzed days. PMN ranged from 0 to 10 , mast cells from 0 to 6 and LMN from 0 to 5/cross section (data not shown). In the PS groups, there was a predominance of PMN in the first four days (Figure-1B). The occurrence of mast cells during all days was not influenced by either PS or saline injection $(\mathrm{p}=0.074)$ (Figure-1C). In contrast, LMN infiltrate was more prominent at the $6^{\text {th }}$ to $14^{\text {th }}$ day (Figure-1D).

\section{DMSO Groups}

Rats treated with DMSO had a significantly reduced grade of edema, vascular congestion and PMN count at the $1^{\text {st }}$ day after PS instillation. At the $7^{\text {th }}$ day, edema, vascular congestion and inflammatory infiltrates (LMN) were also significantly reduced in the DMSO treated-group. Examples of these inflammatory alterations are shown in Figure-2. Conversely, when DMSO was injected in healthy bladders, there was a more pronounced PMN infiltrate at the $1^{\text {st }}$ and $7^{\text {th }}$ days and edema at the $1^{\text {st }}$ day. Mast cell count was increased only on the $7^{\text {th }}$ day in the DMSO group (Table-1).

\section{GAG Measurement}

\section{$P S$ and Control Groups}

Urinary $\mathrm{HA} / \mathrm{Cr}$ levels were higher in all days following intravesical PS injection. There were two peaks of urinary HA excretion, at the $1^{\text {st }}$ day and $7^{\text {th }}$ days. Compared with the levels detected at day 0 animals, $\mathrm{HA} / \mathrm{Cr}$ on the $1^{\text {st }}$ day was increased 2.4-fold and on the $7^{\text {th }}$ day, 2.1-fold $(\mathrm{p}<0.05)$ (Figure-3A).

Urinary S-GAG/Cr followed an almost similar pattern of excretion following PS injection, 


\section{A}

Edema and Vascular Congestion

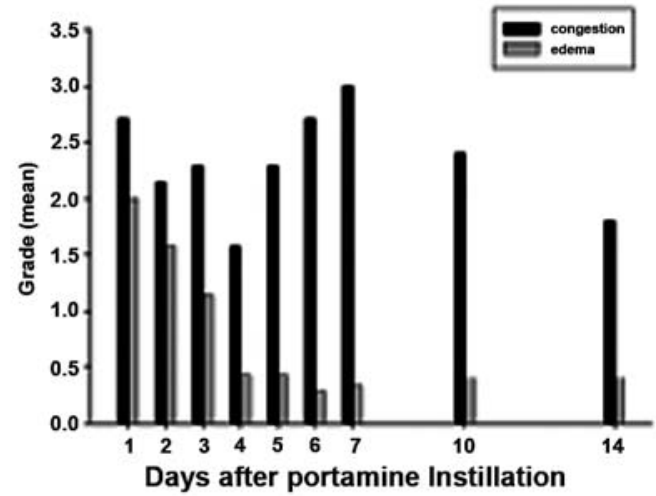

C

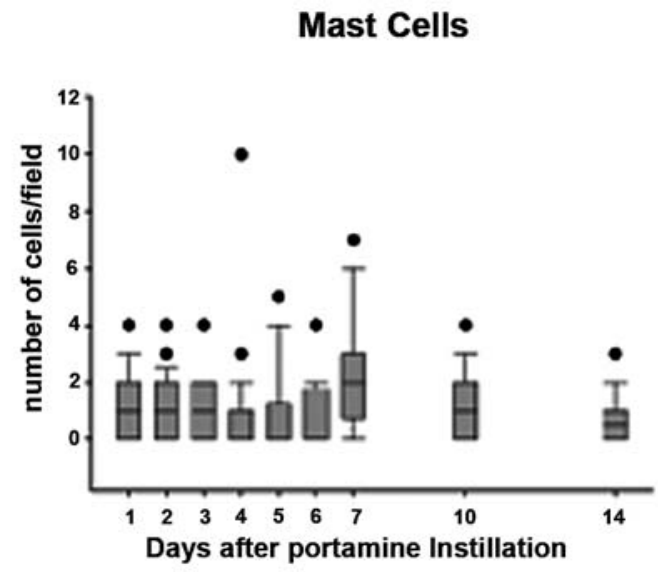

B

PMN

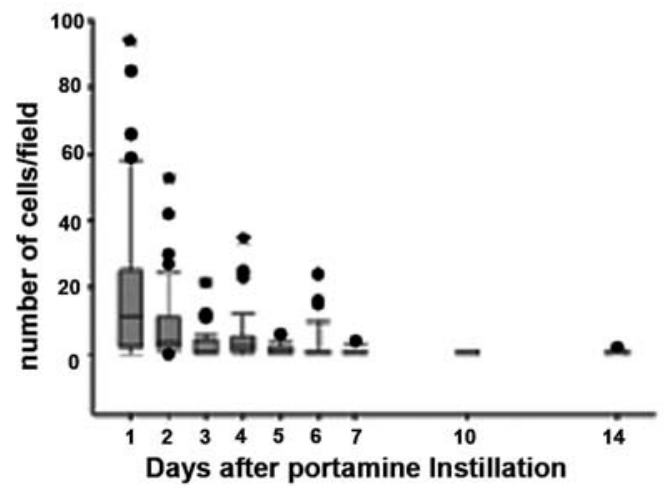

D

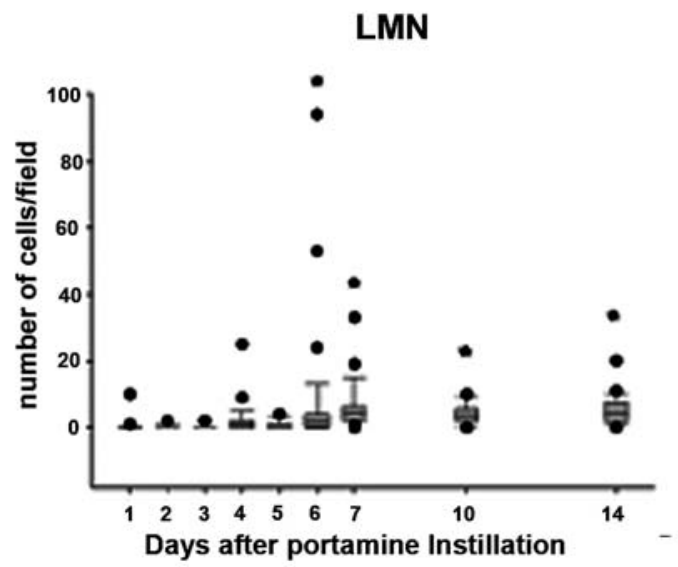

Figure 1 - Histopathological analysis. Time course of effects of intravesical PS instillation on edema and vascular congestion grade (A), on PMN count/field (B), on mast cell count/field (C) and on LMN count/field (D). Values are means in the bars and median with interval (box plots) $* p<0.05$, points on the PS time course vs. those on the control time course.

increasing at the first day with a more remarkable peak at the $7^{\text {th }}$ day. Urinary S-GAG/Cr levels at $7^{\text {th }}$ day were increased 2.1-fold compared to levels on day $0(\mathrm{p}<0.05)$ (Figure-3B).

\section{DMSO Groups}

The instillation of DMSO in healthy bladders provoked an increase in urinary $\mathrm{HA} / \mathrm{Cr}$ levels after 1 and 7 days and an increase of S-GAG/Cr level after 7 days. Animals instilled with PS and treated with DMSO had significantly reduced level of urinary HA only at the $1^{\text {st }}$ day. Urinary S-GAG/Cr levels were similar in all groups (Table-2). There were no differences in urinary creatinine levels between the groups.

\section{COMMENTS}

The polycationic quaternary amine, PS, has a well documented effect of increasing urothelial permeability. PS increased water and urea permeability, reduced the transepithelial resistance, provoked patchy umbrella cell lysis and damage to the tight 
Table 1 - Pathological features in DMSO groups.

\begin{tabular}{|c|c|c|c|c|c|c|c|c|c|c|}
\hline \multirow[t]{2}{*}{ Group } & \multicolumn{2}{|c|}{ Edema (grade) } & \multicolumn{2}{|c|}{$\begin{array}{c}\text { Vascular Congestion } \\
\text { (grade) }\end{array}$} & \multicolumn{2}{|c|}{$\begin{array}{l}\text { PMN Count } \\
\text { (median) }\end{array}$} & \multicolumn{2}{|c|}{$\begin{array}{c}\text { Mast Cell } \\
\text { Count (median) }\end{array}$} & \multicolumn{2}{|c|}{$\begin{array}{l}\text { LMN Count } \\
\text { (median) }\end{array}$} \\
\hline & $\begin{array}{l}1 \text { day } \\
(\mathrm{n}=5)\end{array}$ & $\begin{array}{l}7 \text { days } \\
(\mathrm{n}=5)\end{array}$ & $\begin{array}{l}1 \text { day } \\
(\mathrm{n}=5)\end{array}$ & $\begin{array}{l}7 \text { days } \\
(\mathrm{n}=5)\end{array}$ & $\begin{array}{l}1 \text { day } \\
(\mathrm{n}=5)\end{array}$ & $\begin{array}{l}7 \text { days } \\
(\mathrm{n}=5)\end{array}$ & $\begin{array}{l}1 \text { day } \\
(\mathrm{n}=5)\end{array}$ & $\begin{array}{l}7 \text { days } \\
(\mathrm{n}=5)\end{array}$ & $\begin{array}{l}1 \text { day } \\
(\mathrm{n}=5)\end{array}$ & $\begin{array}{l}7 \text { days } \\
(\mathrm{n}=5)\end{array}$ \\
\hline Saline & $0.6 \pm 0.5$ & $0.4 \pm 0.5$ & $1.2 \pm 0.4$ & $1.0 \pm 1.2$ & 0 & 0 & 1 & 0 & 0 & 0 \\
\hline DMSO & $1.8 \pm 0.8^{*}$ & $1.0 \pm 1.0$ & $2.0 \pm 0.7$ & $1.8 \pm 0.8$ & $3 *$ & $1^{*}$ & 1 & $1^{*}$ & 0 & 0 \\
\hline $\begin{array}{l}\text { PS + } \\
\text { Saline }\end{array}$ & $3.0 \pm 0$ & $1.4 \pm 0.5^{\ddagger}$ & $2.6 \pm 0.5$ & $2.2 \pm 0.4^{\ddagger}$ & $20^{\ddagger}$ & 0 & 0 & 0 & $3^{\ddagger}$ & 0 \\
\hline $\begin{array}{l}\mathrm{PS}+ \\
\mathrm{DMSO}\end{array}$ & $1.6 \pm 0.5$ & $0.4 \pm 0.5$ & $1.4 \pm 0.5$ & $1.2 \pm 0.4$ & 3 & 0 & 0 & 0 & 0 & 0 \\
\hline
\end{tabular}

$* p<0.05$ - saline group X DMSO group at day 1 or 7 (Mann-Whitney U test); ${ }^{*} p<0.05-P S+$ saline group X PS $+D M S O$ group at day 1 or 7 (Mann-Whitney U test), DMSO = dimethyl sulfoxide.

junctions, with reduced expression of uroplakins and ZO-1, in an animal model (10). These findings were also described in biopsies and cell culture obtained from patients with IC (11).

Due to these actions, intravesical instillation of PS could provide an effective and reliable model of urothelial damage. We therefore chose it to study the consequences of the increase of permeability on the urothelium, focusing on bladder inflammation and on urinary GAG behavior.

The histological sections demonstrated a clear difference between PS and control groups. The inflammation was focal in the sections, in accordance with other animal studies and with findings in biopsies from IC patients $(10,12)$. Features associated with IC such as edema and congestion were detectable and significant within the PS groups. There was an apparent temporal evolution of the inflammation, from PMN infiltrate in the first four days to a LMN infiltrate after the $6^{\text {th }}$ day, which lasted until the $14^{\text {th }}$ day. These results demonstrate that even after the removal of PS from the bladder by washing it with saline, there is a persistence of local inflammatory process, possibly due to the increase of permeability and leakage of urinary components.

DMSO, a U.S. Federal Drug and Food Administration-approved intravesical therapy for IC, has been used to provide symptomatic relief of chronic pain in these patients. DMSO has anti-inflammatory and reactive oxygen scavenger actions, crosses membranes easily, impairs the nerve conduction of C-fibers, prevents depolymerization of HA, inhibits angiogenesis of endothelial cells and has local anesthetic properties $(2,13,14)$. However, its mechanism of action and effects on bladder tissue function are not completely understood.

As we found two major peaks of inflammation, we examined the effect of DMSO on these inflammatory changes and also on healthy bladders. DMSO significantly reduced the inflammatory process at both $1^{\text {st }}$ and $7^{\text {th }}$ days after the urothelial injury, which proves its anti-inflammatory action in the bladder. Conversely, this drug provoked mild inflammation in normal mucosa. This finding might support the initial complaint from some patients of exacerbated urethral burning and pelvic pain after DMSO instillation (2).

The GAG layer on the epithelial bladder surface, with its hydrophilic characteristics, is thought to shield the urothelium from microcrystals, proteins, pathogens and noxious substances (15). GAG are composed by repeating disaccharide units, consisting of alternating hexosamine and uronic acid. Hyaluronic acid (HA) is a nonsulfated GAG, most abundantly found in loose connective tissue. In the bladder, HA is more abundant in the underlying connective tissue 

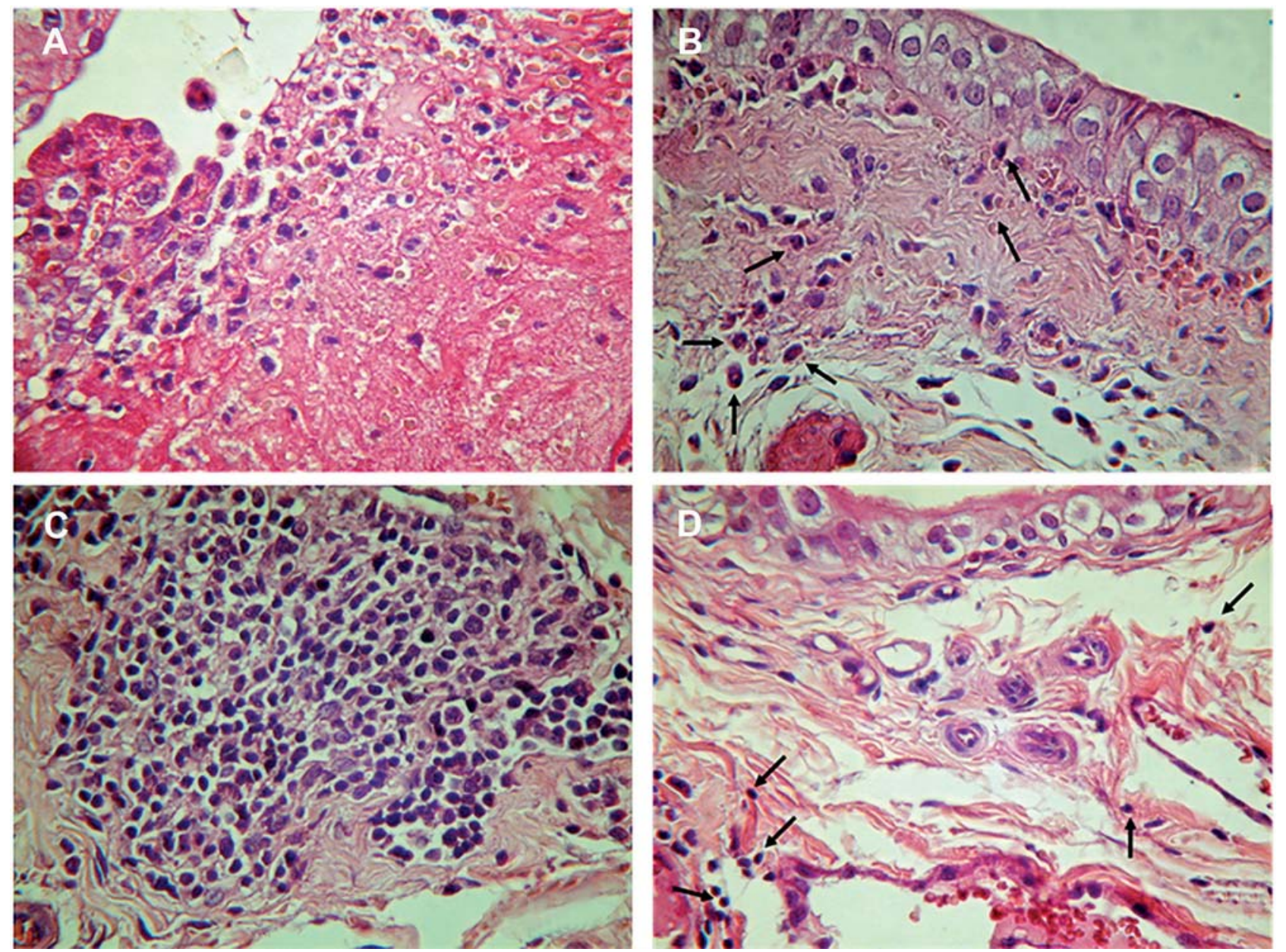

Figure 2-Light microscopy of dimethyl sulfoxide (DMSO) groups. A) PS + saline (1 day) - exulceration of the urothelium with intense neutrophilic infiltrate. Note the complete loss of the urothelial architecture. B) PS + DMSO (1 day) - scarce neutrophils in the lamina propria (arrows). Note the intact urothelium. C) PS + saline (7 days) - exuberant aglomeration of lymphocytes in the lamina propria with some edema in the underlying layers. D) PS + DMSO (7 days), rare lymphocytes in the lamina propria (arrows). Note the intact urothelium. (HE, X400)

of the mucosa and between the smooth muscle layers (16). Sulfated GAG (S-GAG) occur covalently linked to protein cores, forming proteoglycans. The cell surface proteoglycans are composed by proteins and a dense layer of intercalated GAG, forming the so-called GAG layer.

Based on the theory proposed by Parsons et al. of an urothelial deficiency of GAG as an etiological factor for IC (4), urinary concentration of these compounds have been measured in order to establish a disease marker. Despite the hypothesis of a deficient
GAG layer on the cell surface, the amount of GAG in the urine does not necessarily reflect this condition. Different studies have described either decreased or elevated total GAG and HA levels in patients with IC (17). Recently, increased urinary S-GAG and HA levels were associated with severe IC, based on a symptom questionnaire $(18,19)$.

We assessed urinary GAG to verify their excretion in this model of urothelial injury. Urinary HA and S-GAG had a similar pattern of excretion, since two urinary peaks were detected, at the $1^{\text {st }}$ and 

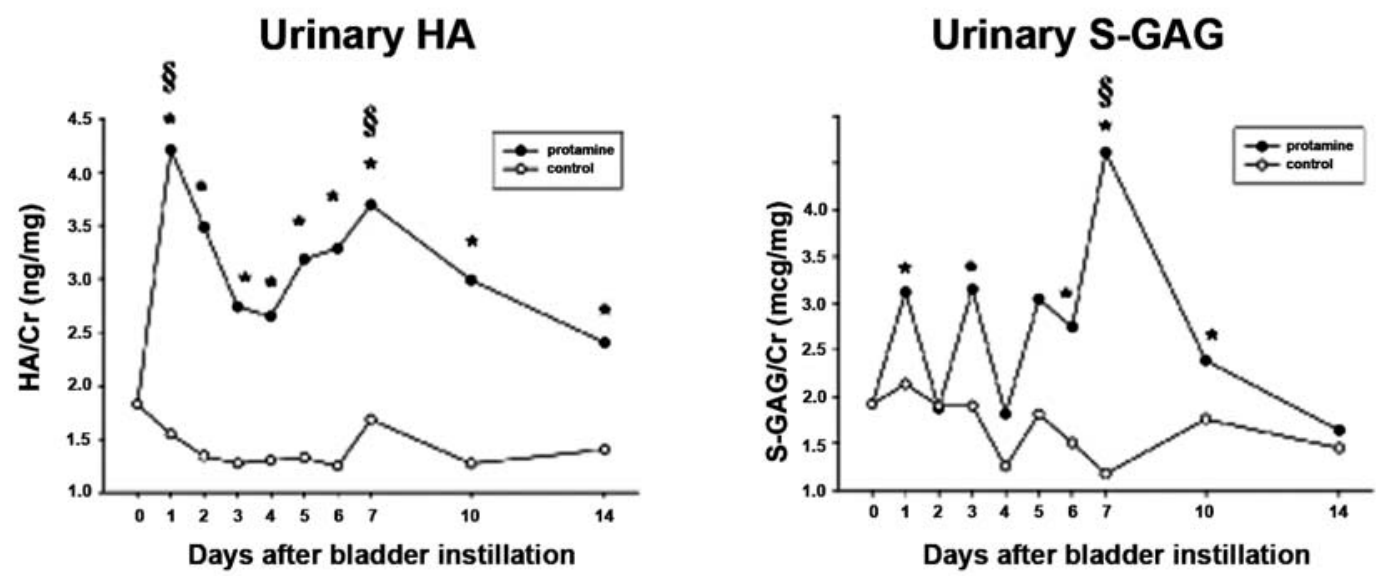

Figure 3 - Urinary GAG measurement. Time course of effects of intravesical PS or saline instillation on urinary HA (A) and urinary $S-G A G(B)$. The concentrations were normalized by urinary creatinine. Values are means $\pm S D . * P<0.05$, points on the PS time course vs. those on the control time course. $\S P<0.05$, comparison between PS groups (HA: day 1 vs. day 0; day 7 vs. day 0) (S-GAG: day 7 vs. days 0, 2, 4 and 14).

at $7^{\text {th }}$ day. These increased levels were concomitant with more pronounced PMN infiltrate and edema, and LMN infiltrate and vascular congestion, respectively. These data might suggest that increased urinary levels may be associated with bladder inflammation.

Urinary HA levels seemed to be associated with the occurrence of PMN infiltrate. DMSO treatment only influenced the urinary HA excretion at the $1^{\text {st }}$ day, concomitantly with reduced PMN infiltrate.
Additionally, higher levels of this compound were associated with this type of inflammatory infiltrate when DMSO was instilled in healthy bladders. DMSO treatment did not influence urinary S-GAG excretion.

$\mathrm{HA}$ also has an influence on inflammation process, such as migration, differentiation, cellular proliferation, angiogenesis and induction of proinflammatory cytokines and chemokines. During inflammation or after injury, HA may either be degraded

Table 2 - Urinary GAG levels in DMSO groups.

\begin{tabular}{lcccc}
\hline Group & \multicolumn{2}{c}{ HA/Cr $(\mathrm{ng} / \mathrm{mg})$} & \multicolumn{2}{c}{ S-GAG $(\mu \mathrm{g} / \mathrm{mg})$} \\
& $\begin{array}{c}\mathbf{1} \text { day } \\
(\mathrm{n}=5)\end{array}$ & $\begin{array}{c}\mathbf{7} \text { days } \\
(\mathrm{n}=5)\end{array}$ & $\begin{array}{c}\mathbf{1} \text { day } \\
(\mathrm{n}=5)\end{array}$ & $\begin{array}{c}\mathbf{7} \text { days } \\
(\mathrm{n}=5)\end{array}$ \\
\hline Saline & $1.6 \pm 0.3$ & $1.5 \pm 0.4$ & $2.0 \pm 0.4$ & $1.3 \pm 0.3$ \\
DMSO & $4.5 \pm 2.2^{*}$ & $6.0 \pm 2.0^{*}$ & $1.9 \pm 0.7$ & $2.6 \pm 0.8^{*}$ \\
PS + Saline & $7.6 \pm 3.0^{\ddagger}$ & $8.6 \pm 2.3$ & $4.3 \pm 1.2$ & $3.8 \pm 0.9$ \\
PS + DMSO & $3.4 \pm 0.7$ & $5.4 \pm 0.7$ & $3.3 \pm 1.3$ & $3.8 \pm 1.9$ \\
\hline
\end{tabular}

${ }^{*} p<0.05$ - saline group X DMSO group at day 1 or 7 (Mann-Whitney U test); ${ }^{*} p<0.05-P S+$ saline group X PS+DMSO group at day 1 or 7 (Mann-Whitney U test); DMSO = dimethyl sulfoxide. 
into smaller weight molecules, by hyaluronidases, or have its synthesis enhanced, by hyaluronan synthases. Degradation could also occur mediated by free radicals (20). As DMSO has an anti-inflammatory effect, depolymerization of HA and is know to be a scavenger of the intracellular hydroxyl radical, the concomitant reduced inflammation and urinary HA levels in the DMSO-treated group might represent an impairment of either degradation or synthesis of this compound.

Sulfated GAG also play role in inflammation and wound healing process. After injury they become soluble as they are released from their protein core. Likewise, their synthesis is also enhanced during inflammation. Both synthesized and released S-GAG participate in different phases of the inflammation and tissue repair (20). The treatment with DMSO did not significantly alter the urinary S-GAG excretion in this experimental model. At the first day after the injury, the higher urinary S-GAG concentration may have corresponded to a desquamation of the superficial urothelial layers that occurred due to the instillation of PS after the treatment with DMSO. The second peak of urinary excretion might represent the urothelial recovery process, in which these compounds may play a part.

Although this is an acute model of urothelial injury and so, not necessarily representative of the IC patient, it supplies valuable information concerning urinary GAG excretion and its relationship with bladder inflammation, validated by the changes occurred after DMSO treatment. In an acute phase there is an increased GAG excretion, which may be observed in phases of worsening symptoms. However, in a chronic phase, GAG production and excretion may reach equilibrium and urinary levels might not reflect any changes.

\section{CONCLUSIONS}

Intravesical instillation of PS promoted focal inflammatory changes, with two distinct types of infiltrate, PMN initially and LMN afterwards. Elevated levels of urinary GAG were associated with bladder inflammation. Two peaks of urinary excretion were concomitant with PMN and LMN infiltrate. The treatment with DMSO reduced these inflammatory changes. This local anti-inflammatory action may be a mechanism by which it exerts a beneficial effect on IC. On the other hand, it caused inflammation in normal mucosa, which could explain the initial flareup of symptoms that some patients relate. Urinary HA levels seemed to be associated with the occurrence of PMN infiltrate, since lower urinary HA levels and reduced PMN infiltrate were concomitant findings after DMSO instillation. DMSO treatment did not influence urinary S-GAG excretion.

\section{CONFLICT OF INTEREST}

None declared.

\section{REFERENCES}

1. Driscoll A, Teichman JM: How do patients with interstitial cystitis present? J Urol. 2001; 166: 2118-20.

2. Rössberger J, Fall M, Peeker R: Critical appraisal of dimethyl sulfoxide treatment for interstitial cystitis: discomfort, side-effects and treatment outcome. Scand J Urol Nephrol. 2005; 39: 73-7.

3. Dietrich CP, Sampaio LO, Toledo OM: Characteristic distribution of sulfated mucopolysaccharides in different tissues and in their respective mitochondria. Biochem Biophys Res Commun. 1976; 71: 1-10.

4. Parsons CL, Lilly JD, Stein P: Epithelial dysfunction in nonbacterial cystitis (interstitial cystitis).J Urol. 1991; 145: 732-5.

5. Fraser MO, Chuang YC, Lavelle JP, Yoshimura N, de Groat WC, Chancellor MB: A reliable, nondestructive animal model for interstitial cystitis: intravesical lowdose protamine sulfate combined with physiological concentrations of potassium chloride. Urology. 2001; 57: 112 .

6. Westropp JL, Buffington CA: In vivo models of interstitial cystitis. J Urol. 2002; 167: 694-702.

7. Peterson MW, Gruenhaupt D: Protamine interaction with the epithelial cell surface. J Appl Physiol. 1992; 72: 236-41.

8. Martins JR, Passerotti CC, Maciel RM, Sampaio LO, Dietrich CP, Nader HB: Practical determination of hyaluronan by a new noncompetitive fluorescencebased assay on serum of normal and cirrhotic patients. Anal Biochem. 2003; 319: 65-72.

9. Dietrich CP, Dietrich SM: Electrophoretic behaviour of acidic mucopolysaccharides in diamine buffers. Anal Biochem. 1976; 70: 645-7. 
10. Lavelle J, Meyers S, Ramage R, Bastacky S, Doty D, Apodaca G, et al.: Bladder permeability barrier: recovery from selective injury of surface epithelial cells. Am J Physiol Renal Physiol. 2002; 283: F242-53.

11. Slobodov G, Feloney M, Gran C, Kyker KD, Hurst RE, Culkin DJ: Abnormal expression of molecular markers for bladder impermeability and differentiation in the urothelium of patients with interstitial cystitis. J Urol. 2004; 171: 1554-8.

12. Rosamilia A, Igawa Y, Higashi S: Pathology of interstitial cystitis. Int J Urol. 2003; 10 (Suppl): S11-5.

13. Parcell S: Sulfur in human nutrition and applications in medicine. Altern Med Rev. 2002; 7: 22-44.

14. Santos NC, Figueira-Coelho J, Martins-Silva J, Saldanha C: Multidisciplinary utilization of dimethyl sulfoxide: pharmacological, cellular, and molecular aspects. Biochem Pharmacol. 2003; 65: 1035-41.

15. Parsons CL, Boychuk D, Jones S, Hurst R, Callahan $\mathrm{H}$ : Bladder surface glycosaminoglycans: an epithelial permeability barrier. J Urol. 1990; 143: 139-42.
16. Laurent C, Hellström S, Engström-Laurent A, Wells AF, Bergh A: Localization and quantity of hyaluronan in urogenital organs of male and female rats. Cell Tissue Res. 1995; 279: 241-8.

17. Akçay T, Konukoglu D: Glycosaminoglycans excretion in interstitial cystitis. Int Urol Nephrol. 1999; 31: 431-5.

18. Lokeshwar VB, Selzer MG, Cerwinka WH, Gomez MF, Kester RR, Bejany DE, et al.: Urinary uronate and sulfated glycosaminoglycan levels: markers for interstitial cystitis severity. J Urol. 2005; 174: 344-9.

19. Lokeshwar VB, Selzer MG, Unwala DJ, Estrella V, Gomez MF, Golshani R, et al.: Uronate peaks and urinary hyaluronic acid levels correlate with interstitial cystitis severity. J Urol. 2006; 176: 1001-7.

20. Taylor KR, Gallo RL: Glycosaminoglycans and their proteoglycans: host-associated molecular patterns for initiation and modulation of inflammation. FASEB J. 2006; 20: 9-22.
Accepted after revision: March 21, 2008
Correspondence address:

Dr. Homero Bruschini

R. Barata Ribeiro, 414 / 35

São Paulo, SP, 01302-000, Brazil

Fax: + $55113218-8283$

E-mail: bruschini@uol.com.br

\section{EDITORIAL COMMENT}

A number of models of urothelial damage have been used to investigate the effects of loss of barrier function. None has been particularly well characterized. This study characterizes the response over several days of the protamine sulfate model and shows that the anti-inflammatory DMSO is capable of markedly reducing the inflammatory response in animals subjected to the urothelial damage protocol. Interestingly, DMSO induces a mild inflammatory response in normal bladder, which may, in part, explain its action in interstitial cystitis in both helping and eventually harming patients.

Dr. Robert E. Hurst Oklahoma University Cancer Institute and Oklahoma University Health Sciences Center Oklahoma City, Oklahoma, USA E-mail: robert-hurst@ouhsc.edu 